\title{
SENTIDO Y ALCANCE DE LA TRANSPOSICIÓN DE LAS DIRECTIVAS DE LA UNIÓN EUROPEA (ANÁLISIS PARTICULAR EN MATERIA DE CONTRATACIÓN PÚBLICA)'
}

\author{
JOSÉ LUIS MARTÍNEZ LÓPEZ-MUÑIZ² \\ Universidad de Valladolid \\ marlomu@der.uva.es
}

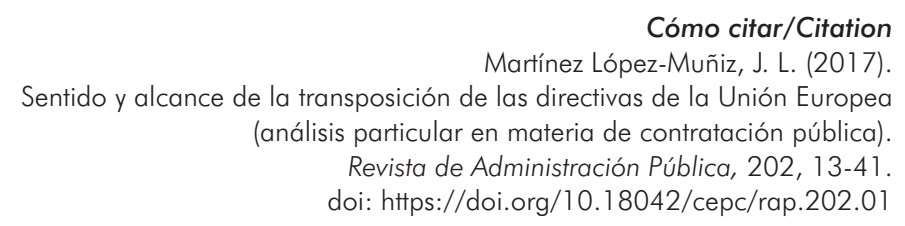

Resumen

La experiencia sobre la transposición de directivas de la Unión Europea al ordenamiento nacional español deja mucho que desear. Parece perderse de vista lo que estas peculiares normas comportan y sus límites. Es usual introducir literalmente sus contenidos en nuestras leyes o reglamentos, sin aparente esfuerzo alguno por encajar adecuadamente sus obligaciones de resultado en las características propias del ordenamiento español, cualesquiera que sean las distorsiones que eso provoque. En este trabajo se proponen parámetros que no debían dejar de tenerse en cuenta, y todo se ilustra con un análisis crítico más particular de la transposición de las directivas sobre contratación pública en algunos de sus aspectos, incluida la problemática actual sobre las concesiones de servicios.

\footnotetext{
1 Elaborado para el Libro homenaje al profesor José Luis Carro Fernández-Valmayor.

2 Catedrático jubilado de Derecho Administrativo. Profesor emérito.
} 


\title{
Palabras clave
}

Directivas; transposición; contratos públicos; concesiones de servicios; contratos de suministro.

\begin{abstract}
Experience about transposition of the European Union directives into Spanish national law is not satisfactory. It seems not to take in account what these peculiar rules involve and their limits. It is usual to introduce their contents literally in statutes or regulations, without any apparent effort to get their obligations of result properly fit the own characteristics of Spanish law system, whatever the distortions that cause. In this contribution parameters are proposed that ought to be taken generally in account, and all is explained on the ground of a more particular critical analysis on the transposition of directives about public procurement in some of their aspects, including the current problems concerning services concessions.
\end{abstract}

\section{Keywords}

Directives; transposition; public procurement; services concessions; public supply contracts. 


\section{SUMARIO}

I. INTRODUCCIÓN. II. INEXISTENCIA DE UNA COMPETENCIA GENERAL DE LA UNIÓN SOBRE EL RÉGIMEN DE LA CONTRATACIÓN DE LOS ESTADOS MIEMBROS Y DE CUANTAS ENTIDADES PÚBLICAS FORMAN PARTE DEL ÁMBITO DE CADA UNO DE ELLOS. III. LEGITIMACIÓN DE LAS DIRECTIVAS SOBRE CONTRATACIÓN PÚBLICA EN CUANTO DIRIGIDAS A LOS OBJETIVOS DE CIERTOS TÍTULOS COMPETENCIALES DE LA COMUNIDAD EUROPEA Y DE LA ACTUAL UNIÓN. IV. RAZÓN DE SER DE LOS TÉRMINOS Y CONCEPTOS EMPLEADOS POR LAS DIRECTIVAS AL SERVICIO DE LOS LIMITADOS OBJETIVOS NORMATIVOS DE ESTAS Y SIN PRETENSIÓN ALGUNA DE DESPLAZAR O CAMBIAR LOS PROPIOS DE CADA ORDENAMIENTO NACIONAL EN LO NO RELEVANTE PARA ELLOS. V. INDEBIDA «ADMINISTRATIVIZACIÓN» DE TODAS LAS COMPRAS PÚBLICAS DE BIENES MUEBLES POR SU INNECESARIA INCLUSIÓN EN EL CONTRATO ADMINISTRATIVO DE SUMINISTROS DEL DERECHO ESPAÑOL. VI. INDEBIDA TRASLACIÓN DE LA PERFECCIÓN DE LOS CONTRATOS PÚBLICOS DESDE SU ADJUDICACIÓN DEFINITIVA A SU FORMALIZACIÓN. VII. PROPÓSITOS INJUSTIFICADOS DE SUPRESIÓN DEL CONTRATO DE GESTIÓN DE SERVICIOS PÚBLICOS Y DE LA ALTERACIÓN DE LA NOCIÓN NACIONAL DE CONCESIÓN ADMINISTRATIVA DE OBRAS O DE SERVICIOS PÚBLICOS.

\section{INTRODUCCIÓN}

Una parte extensa del derecho derivado de la Unión Europea está contenido en directivas.

Las directivas son tipificadas en el actual artículo 288 del TFUE en los mismos términos en que lo fueron ya por parte del artículo 189 del TCEE (249 del TCE tras el Tratado de Amsterdam de 1997), desde su origen en 1957: la directiva obligará al Estado miembro destinatario en cuanto al resultado que deba conseguirse, dejando, sin embargo, a las autoridades nacionales la elección de la forma y de los medios.

Es bien conocida, pues, su diferencia con respecto al reglamento, del que el mismo precepto dice que tendrá un alcance general y será obligatorio en todos sus elementos y directamente aplicable en cada Estado miembro.

En el Tratado de 1951 de la CECA, cuyo diseño organizativo y funcional básico es el origen del aplicado a las Comunidades creadas en 1957 y a la ac- 
tual UE, aunque con algunos cambios, también terminológicos, se distinguió ya, en una formulación análoga que se contenía en su art. 14 - aunque solo para la actuación de la Alta Autoridad-, entre las decisiones, que serían obligatorias en todos sus elementos, y que pudieron ser, conforme a aquel tratado ${ }^{3}$, generales o propiamente normativas ${ }^{4}$ y particulares, y las recomendaciones, de las que se decía que obligarán en cuanto a los objetivos fijados en ellas pero dejarán a sus destinatarios la elección de los medios apropiados para alcanzar tales objetivos. Estas recomendaciones son las que los Tratados de 1957 pasaron a denominar directivas, como es evidente, reconduciendo a la vez el significado de las recomendaciones - tipo de acto que también contemplaron-a la semántica más común de este vocablo, que tal y como se lee hoy en el mismo art. 288 del actual TFUE, lo mismo que en sus precedentes mencionados del TCEE y del TCE, se refiere expresamente a actos sin carácter vinculante alguno.

Aunque la interpretación jurisprudencial ha ido reconociendo desde hace tiempo un cierto efecto directo a las directivas, una vez transcurrido el plazo para su incorporación a los derechos de los Estados miembros, es sabido que se trata solamente del conocido como vertical, de modo que, si de sus formulaciones pueden deducirse obligaciones suficientemente claras y precisas, exigibles a los poderes públicos - lo que es más común cuando se trata de prohibiciones-, podrán serles en efecto exigidas por cualquier sujeto interesado dentro de cada Estado, aunque las normas correspondientes no hayan sido aún integradas o instrumentadas formalmente en su ordenamiento jurídico específicamente propio o lo hayan sido incorrectamente 5 . Pero nunca puede derivarse de una directiva, en sí misma, obligación alguna exigible a los sujetos privados ${ }^{6}$, ni con respecto a otros sujetos privados —el llamado efecto horizontal 7 - ni

3 Así se desprendía, de entrada, de lo dicho en su art. 15, que contemplaba expresamente que tuviesen o no carácter individual, para diferenciar si haría falta su notificación o requerirían publicación.

4 Precedente, por tanto, de los reglamentos comunitarios de las Comunidades de 1957 y de la actual UE. Si bien el Tratado CECA contemplaba expresamente además determinados reglamentos con esta denominación, no solo de organización o régimen interior (arts. 15, 25 o 30), sino también con efectos externos (arts. 65.3 y 66.1, 2 y 3), suscitándose las cuestiones doctrinales a que nos referíamos en «La opción comunitaria por el reglamento y sus implicaciones», en J. M. Alonso Martínez y A. A. Herrero de la Fuente (coords.) (2007), El Tratado de Roma en su cincuenta aniversario (1957-2007) (págs. 200-201), Granada: Comares.

5 SSTJCE Van Duyn, de 4 de diciembre de 1974, Ratti, de 5 de abril de 1979, etc.

6 Al menos desde la STJCE Úrsula Becker, de 19 de enero de 1982.

7 SSTJCE Marshall, de 26 de febrero de 1986, Faccini Dori, de 14 de julio de 1994, o El Corte Inglés, de 7 de marzo de 1996. 
con respecto a los poderes públicos —efecto vertical inverso $0^{8}$ —, salvo por efecto reflejo de la vinculación de estos?

Mucho se ha reflexionado y escrito sobre la especial naturaleza de este tipo de norma comunitaria o de la Unión, que, desde luego, no encuentra parangón posible con nada de lo que suele encontrarse en la tipología normativa de los Estados y que, en cambio, si recuerda algo, es quizá a los acuerdos interestatales de las organizaciones internacionales, no pocos de ellos necesitados, desde luego, de incorporación a los ordenamientos nacionales, aunque no sea más que mediante su formal ratificación, pero también tantas veces mediante diversas medidas ejecutivas ${ }^{10}$.

No pretendemos aquí detenernos en el análisis y caracterización de las directivas. Bastará hacer hincapié en su naturaleza de normas de resultado que, como dice expresamente el Tratado, deben dejar a los Estados miembros la elección de la forma y de los medios para alcanzarlo. Regulan e imponen, pues, un resultado normativo a garantizar, pero han de hacerlo limitándose a determinar lo que se considere necesario para el objetivo o finalidad que marque el Tratado al habilitar la competencia de que se trate, sin descender a más detalles y sin pretender uniformar los ordenamientos estatales más allá de lo requerido estrictamente por dicha finalidad, siempre bajo los principios de subsidiariedad y proporcionalidad (TUE, art. 5). Ha de ser posible que cada Estado garantice el resultado normativo finalista integrándolo en su ordenamiento interno del modo más pertinente y sin alterarlo en lo que no resulte imprescindible.

Pero para que el sistema comunitario o de la Unión funcione correctamente, sin generar problemas innecesarios o complejidades y cambios injusti-

$8 \quad$ STJCE Pretore di Saló, de 17 de octubre de 1986.

9 SSTJCE Fratelli Costanzo, de 22 de junio de 1989 y Smith \& Nephew, de 12 de noviembre de 1996.

10 Las directivas no son, desde luego, acuerdos interestatales o internacionales, sino actos normativos de una persona jurídica supranacional; entran en vigor como cualquier otra norma de la Unión, publicándose en el DOUE-L y una vez que transcurre la vacatio legis (art. 297 TFUE), de modo que pasan así a formar parte del ordenamiento de la Unión y por ello mismo también del ordenamiento de los Estados miembros, pero lo hacen con la peculiaridad de sus limitados efectos, que exigen una instrumentación ejecutiva, una transposición por parte de los Estados miembros para ser plenamente eficaces, sin perjuicio de las responsabilidades en que los Estados puedan incurrir por incumplir este deber. $Y$ es en esta necesidad de transposición o instrumentación ejecutiva en lo que recuerdan a los acuerdos internacionales, que tantas veces contienen obligaciones para los Estados firmantes que los ratifican, pero que requieren medidas ejecutivas para su efectivo cumplimiento. 
ficados, no solamente es necesario que la Unión utilice correctamente las directivas, sin pretender ejercer con ellas un poder normativo que está reservado a los reglamentos, sino que es también imprescindible que en cada Estado se comprenda bien en qué consiste la necesaria transposición de las directivas y se lleve a cabo sin papanatismos y sin caer en la comodidad del simple y acrítico "corta y pega», de modo que no se achaque a la Unión lo que más bien puede ser imputable a la ineptitud e incorrecto hacer de quienes se encargan de la ejecución interna de las directivas, ni se carguen a la Unión objetivos o exigencias que en realidad tengan otro origen.

En España — seguramente no solo aquí- se observa un cierto hábito de incorporar literalmente los contenidos de las directivas a nuestro ordenamiento, sean cuales sean los trastornos que con ello se provoquen, y sin el más leve ejercicio crítico que tenga en cuenta la finalidad y el concreto resultado normativo pretendido por cada directiva, la situación preexistente de nuestro ordenamiento y la medida y la forma en que se deban hacer los cambios necesarios - tras verificar que lo son efectivamente- y al nivel pertinente del ordenamiento.

Las consideraciones que siguen se centran en la operación de transposición de las directivas, para reflexionar sobre cómo deba entenderse su razón de ser y su alcance. Nos limitaremos además a examinar cómo se ha hecho y cómo parece que se pretende de nuevo hacer en uno solo de los muchos campos en que se viene practicando, concretamente el relativo a la contratación pública ${ }^{11}$. Habría que hacer análisis similares sobre lo ocurrido en tantos otros ámbitos en los que el derecho comunitario derivado viene incidiendo en los ordenamientos nacionales a través de directivas. Los hábitos de quienes llevan a cabo su transposición en Espańa no parecen, sin

11 El Consejo de Estado denunciaba recientemente con razón, en su dictamen de 2016 sobre el anteproyecto de Ley de contratos del sector público de 2015, la «oscura y, en ocasiones, inadecuada terminología introducida por la Ley 30/2007 o, incluso, por las normas anteriores, proveniente de las directivas europeas, sin hacer un mínimo esfuerzo de acomodación a nuestra tradición jurídica [...] consecuencia de que la incorporación de las previsiones de las directivas se hace muchas veces con un excesivo carácter mimético, en detrimento de su claridad [...] De ordinario, se opta por la transcripción íntegra, por la remisión global y por las remisiones parciales». Pero "transposición no equivale ni a transcripción ni a traducción literal. La labor de incorporar debe llevar al pre-legislador, primero, y al legislador, después, a adecuar, de una parte, las previsiones de las directivas y decisiones marco a los conceptos materiales, a los criterios formales y sistemáticos de nuestras disposiciones legales y, de otro lado, a ajustar la terminología de su lenguaje jurídico al nacional, no solo por razones lingüísticas sino por mantener la identidad de los conceptos» (ap. II.2, págs. 46-47). 
embargo, en una primera aproximación, muy distintos a los que veremos proyectados en la que se ha venido haciendo en materia de contratación pública. Es probable, por eso, que lo que, en términos algo más abstractos o generales, deduciremos del estudio que expondremos aquí, pueda verificarse también en los demás ámbitos en que inciden las directivas de la Unión. En cualquier caso, permitirá fundamentar criterios razonables que puedan ser exigibles o, al menos, recomendables para la transposición de dichas directivas.

\section{INEXISTENCIA DE UNA COMPETENCIA GENERAL DE LA UNIÓN SOBRE EL RÉGIMEN DE LA CONTRATACIÓN DE LOS ESTADOS MIEMBROS Y DE CUANTAS ENTIDADES PÚBLICAS FORMAN PARTE DEL ÁMBITO DE CADA UNO DE ELLOS}

1. Sabido es que las competencias de la Unión se rigen por un estricto principio de atribución, modulado además, cuando no se le atribuyen en régimen de exclusividad, por los principios de subsidiariedad y proporcionalidad. Estos tres principios son expresamente proclamados principalmente en el art. 5 del TUE, aunque se reiteren expresa o implícitamente en otros diversos artículos de los Tratados de la Unión. En cualquier caso, es evidente que, como afirman de consuno los arts. 4.1 y 5.2 del TUE — nótese esta reiteración tan próxima-, toda competencia no atribuida a la Unión en los Tratados corresponde a los Estados miembros. Pocas cosas dichas con tanta claridad y rotundidad en los Tratados de la Unión. Es, pues, evidente que la Unión no puede llevar a cabo cualquier actuación que sus instituciones u órganos consideren que es necesaria para alcanzar los más o menos amplios fines que los Tratados ponen a su cargo, especialmente en el art. 3 del TUE. Ha de actuar siempre y solo dentro de los limites de las competencias que le atribuyen los Estados miembros en los Tratados para lograr los objetivos que éstos determinan, tal y como textualmente asevera el art. 5.2 del TUE ${ }^{12}$.

2. Las competencias se encuentran atribuidas a la Unión muy principalmente en el TFUE, que, como es bien sabido, es el mismo TCEE de 1957, luego TCE — a partir del Tratado de Maastricht de 1992—, rebautizado con nueva denominación por el Tratado de Lisboa de 2007, en vigor desde di-

12 Sin perjuicio, claro está, de la cláusula de habilitación excepcional de ciertos poderes implícitos contenida hoy en el art. 352 del RFUE, sujetos a severas exigencias formales y límites. 
ciembre de 2009. Hay elementos competenciales de carácter funcional, sobre todo orgánicos - referidos más en particular a las distintas instituciones (arts. 13 y ss.) - en el TUE, pero la determinación de las distintas competencias requiere delimitar no solo su contenido funcional - y, por supuesto, el territorial, aunque este se da aquí generalmente por supuesto-, sino también y muy destacadamente el ámbito material sobre el que las funciones y actividades de que se trate podrán o deberán proyectarse. Y es esta delimitación material —además de otros muchos aspectos del alcance funcional — la que se lleva a cabo en el TFUE - en su extensa Tercera Parte, destacadamente ${ }^{13}$ - . El mismo art. 1 actual del TFUE lo dice netamente cuando anuncia sintéticamente su contenido, afirmando que «el presente Tratado organiza el funcionamiento de la Unión y determina los ámbitos, la delimitación y las condiciones de ejercicio de sus competencias».

3. Con las modificaciones efectuadas por parte del Tratado de Lisboa, el actual TFUE se abre ahora precisamente con un nuevo título I, con el que, siguiendo los pasos del fallido Tratado de 2004 (que trató de hacer lo que llamó —inadecuadamente - una Constitución para Europa), se ha querido satisfacer la reiterada pretensión de que se ordenasen y clarificasen las competencias de la Unión. Está dedicado por ello, con carácter sistematizador y caracterizador general, a las categorías y ámbitos de competencia de la Unión, de modo que en su primer artículo, el art. 2, establece y define esas categorías o tipos de competencias que se distinguen (exclusivas, compartidas, coordinadoras de las politicas económicas y de empleo o sociales de los Estados miembros, y de apoyo, coordinación y complemento de la actuación de los Estados miembros, además de las especiales para definir y aplicar una politica exterior y de seguridad común, incluida la definición progresiva de una política común de defensa), dedicando luego sucesivamente los artículos siguientes $(3,4,5$ y 6$)$ a determinar un anticipo sintético de las materias en que se atribuyen en el Tratado cada uno de los cuatro señalados tipos de competencias, excluidas las relativas a la PESC.

No entraremos a comentar los aciertos y defectos de cuanto se contiene en este título I, que, a todas luces, maneja un criterio clasificatorio singular y con terminología no poco ambigua. No deja de tener, en cualquier caso, utilidades que no es el momento de analizar.

13 Salvo en aspectos relativos a la acción exterior de la Unión y sobre todo en cuanto a la política exterior y de seguridad común (PESC) —incluyendo la llamada política común de seguridad y defensa (art. 42), que, en razón de su muy especial régimen, es objeto de particular atención por el título V del TUE. 
4. Si recordamos sucintamente cuanto queda expuesto es solo para dar a entender mejor lo que ahora afirmaremos sin paliativos: los Tratados configuradores de la Unión - lo mismo que los que instituyeron la Comunidad Económica Europea o la fueron modificando, sustrayéndola incluso, desde 1992, el adjetivo "económica», hasta convertirla en la actual Unión Europea - no han atribuido a la Unión ninguna competencia específica general sobre los contratos que puedan celebrar los Estados miembros y cualesquiera de las entidades o administraciones públicas de sus respectivos ámbitos nacionales, ni sobre el régimen de esa contratación pública. No hay materia alguna de aquellas sobre las que el TFUE otorga competencias a la Unión que pueda entenderse como específicamente comprensiva de cuanto se refiera a los contratos públicos y a su contratación. Basta echar un vistazo a los listados de materias de los mencionados artículos 3 a 6 de dicho Tratado, y completarlo, si hay alguna duda, con la lectura de los más detallados artículos correspondientes de su Tercera Parte. Los contratos públicos y la contratación pública siguen siendo materias bajo la competencia de los Estados miembros, comenzando, por supuesto, por su competencia normativa.

\section{LEGITIMACIÓN DE LAS DIRECTIVAS SOBRE CONTRATACIÓN PÚBLICA EN CUANTO DIRIGIDAS A LOS OBJETIVOS DE CIERTOS TÍTULOS COMPETENCIALES DE LA COMUNIDAD EUROPEA Y DE LA ACTUAL UNIÓN}

1. La inexistencia de una competencia general de la Unión Europea específicamente sobre los contratos públicos y la contratación pública no impide que los Tratados que la instituyen y regulan contengan normas o principios que incidan en esta materia o bien atribuyan a la Unión competencias para imponerle algunas reglas.

Como recordó en 2006 la Comunicación interpretativa de la Comisión Europea 2006/C 179/02 sobre el derecho comunitario aplicable en la adjudicación de contratos no cubiertos o solo parcialmente cubiertos por las directivas sobre contratación pública, «las entidades adjudicadoras de los Estados miembros deben cumplir las normas y principios del Tratado CE en todas las adjudicaciones de contratos públicos que entren en el ámbito de aplicación del mismo [por guardar relación con el funcionamiento del mercado interior $\mathrm{u}$ otros objetivos de su competencia y regulación]. Estos principios incluyen la libre circulación de mercancías (artículo 28 del Tratado CE), el derecho de establecimiento (artículo 43), la libre prestación de servicios (artículo 49), la no discriminación y la igualdad de trato, la transparencia, la proporcionalidad y el 
reconocimiento mutuo» ${ }^{14}$; también la protección judicial efectiva de los derechos que confiere el ordenamiento jurídico comunitario, obviamente ${ }^{15}$. Qué es lo que todo esto exige a los contratos y a la contratación de las entidades públicas, evidentemente resulta bastante indeterminado, aunque haya podido ir pasando a ser algo más determinado a medida que ha sido necesario aplicarlo en conflictos concretos y se ha generado cierta jurisprudencia del Tribunal de Justicia comunitario, hoy de la Unión. Poco es lo que puede entenderse regulado al respecto, por tanto, directamente por los Tratados comunitarios o de la Unión, por importante que sea.

2. Mas, en efecto, algunas de las competencias normativas otorgadas, antes, por el TCE a la CE, o ahora, desde diciembre de 2009, por el TFUE a la UE, han podido servir de base legítima para la aprobación de las varias generaciones de directivas sobre contratación pública que se han venido sucediendo desde los ańos setenta del pasado siglo hasta el último paquete de 2014. Pero siempre solo para reglar determinados aspectos de esa contratación pública o de los contratos públicos — su principal objeto- en los que, en efecto, inciden las competencias normativas o de aproximación normativa (en realidad también normativas) atribuidas a la Unión —antes a la Comunidad Europea.

Por limitarnos ahora a las directivas últimas — las anteriores invocaban los mismos preceptos habilitantes, en su formulación similar anterior-, recordemos sucintamente su base normativa legitimadora.

Tanto la Directiva 2014/24/UE, del Parlamento Europeo y del Consejo, de 26 de febrero de 2014, sobre contratación pública, como la 2014/23/UE, aprobada en la misma fecha por las mismas dichas instituciones, y relativa a la adjudicación de contratos de concesión, se sustentan explícitamente en el TFUE y, en particular, en sus arts. 53.1, 62 y 114.

La invocación de los arts. 53.1 y 62 mira a una misma habilitación normativa, que vale a la vez para garantizar la libertad de establecimiento y la de servicios en el seno del mercado interior europeo, pues, en efecto, el art. 62 no

14 DO C 179, 1.8.2006, pág. 2. Se ha establecido, por ejemplo, como recuerda la Comisión en la misma Comunicación, que «los principios de igualdad de trato y no discriminación por razones de nacionalidad implican una obligación de transparencia que, con arreglo a la jurisprudencia del TJCE (1), "consiste en garantizar, en beneficio de todo licitador potencial, una publicidad adecuada que permita abrir a la competencia el mercado de servicios y controlar la imparcialidad de los procedimientos de adjudicación" " [SSTJCE de 7 de diciembre de 2000 (asunto C-324/98, Telaustria, cdo. 62), de 21 de julio de 2005 (asunto C-231/03, Coname, cdos. 16 a 19) y de 13 de octubre de 2005 (asunto C-458/03, Parking Brixen, cdo. 49)].

15 Ap. 2.3.3 de la citada Comunicación (DO cit., pág. 7). 
hace sino afirmar que una serie de artículos establecidos para la garantía de la primera -entre ellos el 53- serán también aplicables a las materias reguladas por el presente capitulo para garantizar la libertad de prestación de servicios ${ }^{16}$.

Por si esta cláusula habilitante no fuera suficiente se invoca también la más general del art. 114, en orden al efectivo establecimiento y garantía del funcionamiento del mercado interior - como espacio sin fronteras interiores, en el que la libre circulación de mercancías, personas, servicios y capitales estará garantizada de acuerdo con las disposiciones de los Tratados - a que se refiere el actual art. 26 TFUE. Con este fin, en efecto, según el art. 114, salvo que los Tratados dispongan otra cosa, el Parlamento Europeo y el Consejo, con arreglo al procedimiento legislativo ordinario y previa consulta al Comité Económico y Social, adoptarán las medidas relativas a la aproximación de las disposiciones legales, reglamentarias y administrativas de los Estados miembros que tenga por objeto - reitera expresamente- el establecimiento y el funcionamiento del mercado interior. Un mercado interior al que, por lo demás, le será consustancial el régimen de competencia que se ocupa de regular y garantizar precisamente todo el título VII de la Tercera Parte del TFUE (art. 101), del que forma parte este mismo art. 114. De modo que no sorprende que la motivación de las citadas directivas enfatice su finalidad de garantizar una apertura a la competencia de la contratación que regulan, que no deja de conectarse, por cierto, a la vez, con el objetivo de incrementar la eficiencia en el gasto público, especialmente relevante ahora en la llamada Estrategia Europa 2020, establecida en una Comunicación de la Comisión de 3 de marzo de 2010 titulada «Europa 2020, una estrategia para un crecimiento inteligente, sostenible e integrador» ${ }^{17}$.

Las habilitaciones mencionadas han estado así sustancialmente desde 1957, aunque haya cambiado el órgano competente y el procedimiento para adoptar las directivas, como una manifestación más de la progresiva participación que, desde el Acta Única Europea de 1986 y, sobre todo, el Trata-

16 El 53.1 afirma que «a fin de facilitar el acceso a las actividades no asalariadas y su ejercicio, el Parlamento Europeo y el Consejo, con arreglo al procedimiento legislativo ordinario, adoptarán directivas para [...] la coordinación de las disposiciones legales, reglamentarias y administrativas de los Estados miembros relativas al acceso a las actividades por cuenta propia y a su ejercicio». Y por lo dicho en el citado art. 62 se entiende que esa finalidad de facilitar el acceso - en las condiciones de igualdad y no discriminación por la nacionalidad entre los nacionales de Estados miembros-, que, de modo general, reclama ahora destacadamente el art. 18 del mismo TFUE, se aplica tanto al establecimiento en cualquiera de los territorios de los Estados como para la prestación de los servicios desde cualquiera de ellos a destinatarios situados en otro u otros.

17 Cfr. considerando 2 de la Directiva 2014/24/UE; en términos similares, véase el considerando 1 de la 2014/23/UE. 
do de Maastricht de 1992, ha ido adquiriendo el Parlamento Europeo en su adopción, antes competencia de solo el Consejo, previo dictamen meramente consultivo de la Asamblea, origen del actual Parlamento. La actual redacción, con todo, del 114, contiene varios apartados en los que, especialmente con referencia a los niveles de protección del medio de trabajo o del medio ambiente que se contengan en esas directivas, pero no solo —al tiempo que se habilita el establecimiento de un nivel de protección elevado en varios de esos campos-, se contienen previsiones de especial consideración para con las posiciones o intereses de los Estados miembros sujetos a esa armonización, en las que ahora no es necesario entrar, pero que revelan también el peculiar modo de ser de las directivas, por más que, desde el Tratado de Lisboa, puedan recibir la adjetivación impropia de legislativas siempre que sean adoptadas con alguna intervención del Parlamento además del Consejo, aunque no sea, en algunos supuestos — no el del art. 114_, sino consultiva (art. 289 TFUE).

3. Todo lo que pueda o deba ser armonizado, aproximado o coordinado, en suma, por la mencionadas directivas, conforme a esas previsiones del TFUE, habrá de ser fijado como obligación de resultado para los Estados miembros en el plano normativo, y necesitará venir justificado en el señalado objetivo de promover y garantizar que los contratos que oferten y celebren las entidades públicas de los distintos Estados miembros se adjudiquen o celebren, en principio, con apertura igual a cualquier sujeto o empresa interesada del ámbito de los Estados miembros, con la publicidad necesaria para ello, con plazos que razonablemente permitan a cualquiera informarse y presentar sus candidaturas y proposiciones, sin preferencias ni ventajas directa o indirectas por razón de la nacionalidad o de su asentamiento en el territorio. Las excepciones convendrá regularlas. Como podrá también regularse la modificación y otras incidencias de la ejecución o incluso la extinción de tales contratos en orden a garantizar la efectividad de la regulación que se unifique en cuanto a su celebración (y solo para eso), o los medios jurídicos necesarios que garanticen el respeto y cumplimiento de todas estas normas por los Estados miembros. Pero nada más.

4. Aunque no se invoquen formalmente por las directivas mencionadas como base legal, al inicio de su motivación, sino los preceptos del TFUE mencionados, lo cierto es que no dejan de sustentar a la vez alguna de sus determinaciones en otras previsiones competenciales del mismo Tratado, aunque, como ya hemos apuntado, el mismo art. 114 ya habilita expresamente para que la aproximación normativa correspondiente a operar por las directivas de que se trata incida en concreto en materia de salud, seguridad, protección del medio ambiente y protección de los consumidores basándose en un nivel de pro- 
tección elevado, teniendo en cuenta especialmente cualquier novedad basada en hechos cientificos ${ }^{18}$. En cualquier caso, el art. 7 del mismo TFUE impera que la Unión velará por la coherencia entre sus diferentes politicas y acciones, teniendo en cuenta el conjunto de sus objetivos, si bien siempre observando el principio de atribución de competencias, dentro de las cuales ha de moverse siempre - ya lo hemos dicho - toda actividad normativa o ejecutiva de la Unión.

\section{RAZÓN DE SER DE LOS TÉRMINOS Y CONCEPTOS EMPLEADOS POR LAS DIRECTIVAS AL SERVICIO DE LOS LIMITADOS OBJETIVOS NORMATIVOS DE ESTAS Y SIN PRETENSIÓN ALGUNA DE DESPLAZAR O CAMBIAR LOS PROPIOS DE CADA ORDENAMIENTO NACIONAL EN LO NO RELEVANTE PARA ELLOS}

1. Obviamente las directivas de la Unión tienen que establecer sus normas, determinando las consiguientes obligaciones de resultado a que se refiere el art. 288 TFUE, mediante el uso de una serie de términos significativos de los correspondientes conceptos con los que se acote y determine cuanto haya de ordenarse o prohibirse. El derecho requiere del lenguaje, se plasma en él, y no puede existir en realidad de otro modo.

Dada la creciente diversidad de tradiciones jurídicas que se aúnan en el derecho de la Unión, se comprende que las directivas se hayan sentido en la necesidad de establecer sus propias guías conceptuales de los términos que emplean, a los efectos de que todos sus destinatarios puedan interpretar unívocamente lo que expresan. De otro modo se frustraría totalmente su propia razón de ser parcialmente unificadora — siempre en los mínimos suficientemente necesarios (tal y como exigen los principios de subsidiariedad y proporcionalidad proclamados en el art. 5 TUE) — de tan diversos sistemas y ordenamientos jurídicos.

2. Hace tiempo que las directivas sobre contratación pública se abren también con listados, cada vez más largos, de fijaciones conceptuales de sus

18 Ya hemos hecho referencia, por ejemplo, al énfasis que la motivación de las directivas citadas de 2014 pone en la consecución de una mayor eficiencia en el gasto público que se encauza por los contratos públicos. Es algo que viene imperado por el art. 119.3 del TFUE cuando afirma como uno de los principios rectores de la política económica y monetaria el de finanzas públicas sólidas, y por el 120, que es uno de los que proclama el principio de una economía de mercado abierta y de libre competencia, favoreciendo una eficiente asignación de recursos. 
términos. Así, el art. 2 de la Directiva 2014/24 llena casi dos páginas del DO con definiciones ${ }^{19}$.

En unos u otros Estados la significación de unos u otros de estos términos puede ser la misma que emplea la Directiva, pero puede ocurrir también que tales términos no existan en su legislación o que tengan una significación diferente. No hay que concluir de entrada por ello que estén obligados a recibir tales términos en su legislación y a ajustar su significación a la usada por la Directiva. La perspectiva conceptualizadora del legislador nacional y la de quien ejerce el poder normativo mediante la Directiva no tienen por qué ser necesariamente iguales, siempre que cada Estado acomode su ordenamiento interno a cuantas obligaciones de resultado normativo deriven de la Directiva de modo real y sustantivo.

Además de esos listados de definiciones hay otros muchos preceptos de la misma Directiva citada, empezando por su artículo 1, que contienen otras varias, de cuyos términos y significado hay que decir lo mismo. Los Estados están vinculados a la sustancia de lo ordenado o prohibido, no a la terminología utilizada.

Un vistazo a la Directiva 2014/23 confirma el uso de las mismas técnicas. También esta tiene un artículo 5 dedicado a definiciones, aunque tampoco sean las únicas relevantes que hay en el conjunto de su contenido. En el listado conceptual del art. 5 encontramos las concesiones, tanto de obras como de servicios, además de varios de los términos ya definidos en la Directiva 2014/24 - este es, por cierto, uno de los inconvenientes de esta técnica: la reiteración en directivas distintas de la definición de unos mismos términos, con riesgo de variantes- y otros como derecho exclusivo o derecho especial.

3. Retengamos, en fin, que el poder normativo de la Unión no puede en ningún caso pretender modificar los ordenamientos estatales mediante la imposición de términos y conceptos que considere necesario utilizar en sus directivas, si carece de título competencial habilitante para operar tal tipo de cambios. Incurriría en abuso de competencia contra derecho cualquier institución de la Unión, incluido el Tribunal de Justicia, que lo pretendiese.

19 Que incluyen los términos poderes adjudicadores, autoridades, órganos y organismos estatales, poderes adjudicadores subcentrales, organismo de derecho público, contratos públicos, contratos públicos de obras, obra, contratos públicos de suministro, contratos públicos de servicios, operador económico, licitador, candidato, pliego de contratación, actividades de compra centralizadas, actividades de compra auxiliares, central de compras, proveedor de servicios de contratación, escrito, por escrito, medio electrónico, ciclo de vida, concurso de proyectos, innovación, etiqueta, requisitos aplicables a efectos de la etiqueta, autoridades regionales. 
Pues bien, muy equivocadamente el legislador español lleva a cabo la tarea de transposición de directivas comunitarias sin tener en cuenta suficientemente cuanto queda expuesto, que tiene un alcance general aunque lo hayamos ilustrado solamente con particular referencia a las directivas sobre contratación pública. Nos referiremos a continuación a algunos de los resultados a que ha llevado esta defectuosa transposición en esta misma materia.

\section{INDEBIDA «ADMINISTRATIVIZACIÓN» DE TODAS LAS COMPRAS PÚBLICAS DE BIENES MUEBLES POR SU INNECESARIA INCLUSIÓN EN EL CONTRATO ADMINISTRATIVO DE SUMINISTROS DEL DERECHO ESPAÑOL}

1. Ya desde la primera operación de transposición de las directivas de contratación pública al entrar España en las Comunidades Europeas en 1986, se incurrió manifiestamente en una tan injustificada como perturbadora desfiguración del contrato administrativo español de suministros, cuyo contenido se amplió en contradicción con su propia significación tradicional hasta incluir contratos que para nada requerirían la calificación de administrativos, injustificable para ellos ${ }^{20}$.

El contrato público de suministros, calificado como administrativo en la Ley de contratos del Estado de 1965, se definía como la compra de bienes muebles por la Administración en la que concurra alguna de las siguientes características: 1. Que el empresario se obligue a entregar una pluralidad de bienes, de forma sucesiva y por precio unitario, sin que la cuantía total se defina con exactitud al tiempo de celebrar el negocio por estar subordinadas las entregas a las necesidades de la Administración; 2. Que se refieran a bienes consumibles o de fácil deterioro por el uso. 3. Que la cosa o cosas que hayan de ser entregadas por el empresario deban ser elaboradas con arreglo a caracteristicas peculiares fijadas por la Administración. A lo que el mismo art. 83 que hacía esta definición añadía expresamente - por si hubiera alguna duda - que las restantes adquisiciones de bienes muebles se regirán por la Ley del Patrimonio del Estado. El contrato

20 F. Sosa Wagner (1996) ya hizo notar el origen europeo de «la inacabable extensión del concepto de suministro» en El contrato público de suministro, Madrid: Civitas, pág. 37, aun sin particular crítica de sus consecuencias. Análogamente, L. Cosculluela Montaner (1996), «El contrato de suministro», en R. Gómez-Ferrer Morant (dir.), Comentario a la Ley de contratos de las Administraciones Públicas (págs. 783-825), Madrid: Civitas, y (2004), 2a ed. de la misma obra (págs. 981-1034), Madrid: Civitas, Thomson. 
tipificado en el n. 3 es el conocido como contrato de fabricación; el suministro más propiamente dicho es el del n. 1, aunque también haya sido frecuente incluir el tipificado en el n. 2 por razón del dicho carácter consumible del bien, por más que no deje de tener este término una significación bastante relativa.

Pues bien, el Real Decreto Legislativo 931/1986, de 2 de mayo, por el que se modificó aquella ley para adaptarla a las directivas comunitarias entonces vigentes sobre contratos públicos de obras y suministros — en virtud de la delegación operada por Ley 47/1985, de 27 de diciembre- pasó a definir el contrato administrativo de suministro como la compra de toda clase de bienes muebles por parte de la Administración, salvo la adquisición de propiedades incorporales y los títulos representativos de capital, que se regirán por la Ley del Patrimonio del Estado. Las tres figuras a que hasta entonces se había limitado ese contrato pasaron entonces simplemente a constituir supuestos que, desde luego, en todo caso — faltaba más! - se considerarán como contrato de suministro. La ampliación de este tipo contractual, con la consecuencia de desfigurar la noción misma de suministro y de atraer toda compraventa de bienes muebles al ámbito de los contratos administrativos, sin necesidad ni justificación alguna, fue un hecho consumado desde entonces. Reformas posteriores — también consecuencia de modificaciones de la directiva comunitaria correspondiente- han ido ampliando aún más este tipo contractual, hasta comprender cuanto hoy se incluye en él en el art. 9 del Texto Refundido de 2011 de la Ley de contratos del sector público: cualquier contrato que tenga por objeto la adquisición, el arrendamiento financiero, o el arrendamiento, con o sin opción de compra, de productos o bienes muebles, si bien siguen excluidos los contratos relativos a propiedades incorporales $o$ valores negociables y se excluyen también los contratos de adquisición de programas de ordenador desarrollados a la medida, que se considerarán contratos de servicios.

No es cuestión de entrar ahora con detalle en identificar lo que debería estar dentro o no del contrato público de suministro y de su consideración como contrato administrativo. Bastará con que señalemos que si el contrato es de tracto instantáneo y no de tracto sucesivo, tiene poco sentido tanto su denominación castellana como suministro como, sobre todo, su inclusión entre los contratos administrativos.

Lo que queremos sobre todo es destacar cómo el legislador español, al transponer las directivas comunitarias al respecto, se ha limitado a copiar sin más el concepto acotado por estas con las palabras de contrato de suministro, sin entrar en más distinciones ni plantearse más cuestiones sobre la razón justificante de la normativa comunitaria y el alcance con el que puede pretender obligar en el ordenamiento español.

2. Que las sucesivas directivas comunitarias que han dado ciertas normas para lo que han denominado contrato público de suministros — siempre que, 
por supuesto, alcance la cuantía que ellas mismas indican y no quede excluido por las exclusiones que en ellas se hacen - hayan querido claramente incluir desde el principio cualquier adquisición de bienes muebles de todo tipo por un poder público —o equivalente a sus efectos-, excluidos los ya mencionados, y luego, incluso el arrendamiento financiero o el arrendamiento con o sin opción de compra, solo quiere decir que obligan a los Estados a someter, al menos, a las normas que las directivas han ido estableciendo, a los contratos que tengan ese objeto, cualquiera que sea su denominación en el ordenamiento nacional y cualquiera que sea el régimen que tengan en este en cuanto a su cumplimiento o ejecución, interpretación, modificación o extinción, que es, como se sabe, para lo que es relevante su calificación en España - y en algunos otros países - como administrativo o no (artículos 19.2 y 20.2 del TR citado de la Ley de contratos del sector público).

Ninguna directiva ha obligado ni ha podido obligar a que la legislación española se decante a todos los efectos por el término ni por la noción de contrato público de suministros que en ellas se contenga. Ese término y ese concepto de las directivas solo tiene un cometido, una razón de ser: delimitar el tipo o tipos de contratos que habrán de someterse en los Estados a las normas que ellas establecen como reglas mínimas. Luego cada Estado, al ejecutar o transponer cada directiva, hará que, en efecto, se ajusten a esas normas todos los contratos - les llame como les llame, les rija o regule en otros aspectos de una u otra manera- cuyo objeto sea el acotado en la noción configurada y definida en la directiva correspondiente, y tenga la cuantía necesaria. Y así, ninguna necesidad — ninguna obligación con la Unión — había ni hay de que en el derecho español la compraventa de vehículos, por ejemplo, o de máquinas muebles, o de mesas, o de armarios, etc., por una Administración — si no son contratos de fabricación - no sean contratos públicos no administrativos, sometidos en todo su cumplimiento y efectos al derecho privado, civil o mercantil que corresponda, y hayan de ser, en cambio, como ocurre desde 1986, contratos administrativos, con no poca incongruencia con lo que esta categoría comporta. Tendrán que someterse, desde luego — si son de la cuantía en que se aplica la Directiva- a cuantas normas establece la Directiva para los contratos públicos de suministro en cuanto a su contratación $-\mathrm{y}$ ahora también respecto a su modificación y aspectos de su ejecución- pero no por ello tienen por qué ser en el ordenamiento español — repetimos - contratos administrativos de suministro ni, más en general, contratos denominados de suministro. El que así sea desde 1986 no es sino una muestra de la falta de comprensión de nuestro legislador de qué son las directivas y cómo deben transponerse. 


\section{INDEBIDA TRASLACIÓN DE LA PERFECCIÓN DE LOS CONTRATOS PÚBLICOS DESDE SU ADJUDICACIÓN DEFINITIVA A SU FORMALIZACIÓN}

1. Como ya pusimos de manifiesto hace unos años ${ }^{21}$, tampoco se justifica en rigor toda la reforma legislativa de agosto de 2010 en exigencias contenidas en las directivas comunitarias y en concreto en la Directiva conocida como de $\left\langle\right.$ recursos ${ }^{22}$, antes y después de su casi completa nueva redacción por la Directiva 2007/66/CE, del Parlamento Europeo y del Consejo, de 11 de diciembre de 2007.

Esta Directiva, ahora de manera explícita, y la jurisprudencia que la ha interpretado y aplicado ya en su versión inicial, donde no se decía de manera expresa $^{23}$, han exigido, con buena lógica, que transcurra al menos un plazo obligatorio de diez días desde que se adjudique cualquiera de los contratos públicos sometidos a las directivas y lo que denominan su celebración, entendida, como hemos explicado en su momento, como el acto que permite ya la ejecución del contrato y, en consecuencia, los posibles hechos consumados que hacen difícil o imposible — en algunos sistemas jurídicos de determinados Estados de la Unión incluso jurídicamente imposible- que su anulación sea verdaderamente efectiva.

El legislador español, autor de la Ley 34/2010, de 5 de agosto, en lugar de atenerse a la interpretación finalista que requiere siempre toda directiva para procederse a su adecuada inserción en el ordenamiento nacional, cedió una vez más a la comodidad y simplismo de trasladar literalmente palabras,

21 J. L. Martínez López-Muñiz (2011), «El nacimiento de los contratos públicos: reflexiones sobre una equivocada transposición de la Directiva comunitaria "de recursos"”, Revista de Administración Pública, 185, págs. 345-363, y en J. M. de la Cuétara Martínez, J. L. Martínez López-Muñiz, y F. Villar Rojas (coords.), Derecho administrativo y Regulación económica (Liber amicorum Gaspar Ariño Ortiz), Madrid: La Ley, págs. 339-363.

22 Directiva 89/665/CEE, del Consejo, de 21 de diciembre de 1989, relativa a la coordinación de las disposiciones legales, reglamentarias y administrativas referentes a la aplicación de los procedimientos de recurso en materia de adjudicación de los contratos públicos de suministros y de obras. La legislación española — la plasmada en el TR de 2000 de la Ley de contratos de las administraciones públicas, pero en una regulación que se reiteraría en la Ley 30/2007 de contratos del sector público- fue considerada contraria a dicha Directiva —en su versión original— por STJCE de 3 de abril de 2008, asunto C-444/06, Comisión-España.

23 La Sentencia Alcatel Austria y otros, de 28 de octubre de 1999, del TJCE, como exponemos en el trabajo citado, sería el verdadero leading case. 
conceptos y mandatos, sin tener en cuenta su posible distinta significación en su uso instrumental tanto en la jurisprudencia del TJCE como en la Directiva 2007/66/CE, al objeto de delimitar la obligación normativa de resultado que se impone a los Estados miembros; olvidando también la dependencia lexicológica y conceptual de quienes redactan las directivas y las sentencias de la hoy Unión respecto de una pluralidad de sistemas jurídicos nacionales y de distintas tradiciones jurídicas, que hay que saber discernir y aquilatar para identificar adecuadamente el alcance de las obligaciones de resultado que legítimamente imponen o pueden imponer las directivas.

2. Como hemos explicado en el trabajo ya aludido y en otras publicaciones ${ }^{24}$, en el derecho administrativo español la adjudicación de todo contrato público (administrativo o no) ha venido siendo, al menos desde la Ley de Contratos del Estado de 1965, pero incluso desde antes, el acto constitutivo del contrato, por el que este se perfecciona - como decían literalmente nuestras sucesivas leyes y en concreto el art. 27.1 de la Ley 30/2007_-, y, en consecuencia, la adjudicación del contrato ha coincidido siempre con lo que también podría llamarse la celebración de ese mismo contrato, a partir de cuyo momento el contrato obviamente obligaba como tal a las partes, en los términos dispuestos por la Ley. La exigencia adicional de una formalización de ese mismo contrato nunca fue en nuestro derecho un requisito para la constitución, nacimiento, perfeccionamiento o celebración del contrato, sino solo para su plena eficacia, un requisito, pues, solo, si se quiere, ad probationem, no ad solemnitatem. Así se había venido regulando y se establecía en concreto claramente en el art. 140 de la Ley 30/2007. Con la formalización se abría la posibilidad de ejecución efectiva del contrato. Y si bien la Ley siempre estableció un plazo máximo para ella — lo hacía dicho art. 140_- de modo que, de no formalizarse en ese tiempo por culpa del contratista, podría producirse

24 Más detenidamente desde J. L. Martínez López-Muñiz (1998), «Naturaleza de los contratos públicos a la luz del Derecho español, su fundamento y consecuencias», en J. C. Cassagne (dir.), Derecho Administrativo (obra colectiva en homenaje al profesor Miguel S. Marienhoff) (págs. 947-969), Buenos Aires: Abeledo-Perrot; y luego en (2006), «La adjudicación», en J. C. Cassagne y E. Rivero Ysern (dirs.), La contratación pública, 2, (págs. 681-721), Buenos Aires: Hammurabi, y (2008), «Naturaleza jurídica del contrato público», en AA.VV., La contratación administrativa en España e Iberoamérica (págs. 481-522), London: Cameron May y Junta de Castilla y León, o (2010), «La causa jurídico-pública de los contratos públicos», en AA.VV., Modernizando el Estado para un país mejor (IV Congreso Nacional de Derecho Administrativo) (págs. 675-705), Lima: Palestra, y en la Revista de Derecho Público (Ed. Jurídica Venezolana), 121, págs. 41-65. 
la resolución del contrato, no se preveía ningún tiempo mínimo obligado de espera para esa formalización y consiguiente comienzo de la ejecución del contrato. Las exigencias de la Directiva de recursos comportaban, sin lugar a dudas, que había que establecer al menos un plazo de 10 de días - desde la recepción efectiva de la notificación de la adjudicación por parte de los licitadores $^{25}$ - para que pudiera procederse a esa formalización y ulterior ejecución del contrato, en orden a cumplir la razonable obligación de resultado que la Directiva, implícitamente en su versión original, y de modo expreso tras su reforma en 2007, imponía, para que los posibles recursos contra la adjudicación no resultasen de hecho inútiles. Cumplir esa exigencia por parte del legislador español era bien sencillo: habría bastado con introducir simplemente ese plazo mínimo u otro algo superior como requisito imprescindible para proceder a la formalización y ulterior ejecución del contrato, como lo ha hecho en efecto el artículo 156.3 de la vigente Ley de contratos del sector público desde su reforma en agosto de 2010 — sin necesidad, por lo demás, de limitarlo a los contratos «sujetos a regulación armonizada»— y previendo claramente la posibilidad de acudir a un órgano para-jurisdiccional administrativo como los previstos ahora por el art. 41 de la Ley de contratos o a un órgano judicial contencioso-administrativo directamente para obtener de manera sumarísima y urgente protección frente al incumplimiento. Algo que podría haberse regulado también bastante más simplemente que del modo en que se ha hecho con los actuales arts. 37 y ss. de la Ley de contratos. Pero nada de eso requería ni justifica trasladar la perfección del contrato a la formalización del contrato como se ha hecho en el actual art. 27 de la Ley de contratos a partir de la mencionada reforma de 2010, aun con las incoherencias y contradicciones que se han mantenido con otros preceptos de la misma Ley, que señalábamos en el estudio a que hemos hecho referencia.

\section{PROPÓSITOS INJUSTIFICADOS DE SUPRESIÓN DEL CONTRATO DE GESTIÓN DE SERVICIOS PÚBLICOS Y DE LA ALTERACIÓN DE LA NOCIÓN NACIONAL DE CONCESIÓN ADMINISTRATIVA DE OBRAS O DE SERVICIOS PÚBLICOS}

1. Una última manifestación de esta equivocada manera de entender y ejecutar o transponer las directivas sobre contratación pública en la que nos detendremos por su especial trascendencia resulta del Anteproyecto de Ley de

25 Nuevo artículo 2 bis de la Directiva 89/665/CE, del Consejo, introducido por la Directiva 2007/66/CE del Parlamento Europeo y del Consejo, de 11 de diciembre de 2007. 
contratos del sector público aprobado por el Consejo de Ministros de 17 de abril de 2015.

2. Ya es, desde luego, más que discutible la compleja forma por la que han optado las instituciones de la Unión para hacer entrar en el ámbito de las directivas sobre contratación pública ciertos contratos, que han dado en llamar concesiones de servicios, a cargo de entidades públicas - formal o sustancialmente tales - o incluso de operadores de servicios con derechos exclusivos o especiales de los sometidos ahora a la Directiva 2014/25/UE, tal vez para supuestamente mejor vencer o sortear la tradicional resistencia que a ello habían opuesto algunos Estados, y especialmente Francia, por su particular concepción de tales concesiones como delegaciones de poder público, cuya exclusión del derecho comunitario quedaría amparada por lo que hoy es el artículo 51 del TFUE ( 45 y, antes, 55 del TCE). Cabe, sin embargo, preguntarse, a la vista de las concesiones finalmente excluidas de esa nueva Directiva, si no estamos ante un verdadero parto de los montes.

Para tal finalidad - muy limitadamente alcanzada — ninguna falta había hecho, por lo demás, romper la unidad que habían logrado, cada una en su ámbito, las Directivas 2004/18/CE y 2004/17/CE (además de, por su parte, la Directiva 2009/81/CE, en el ámbito de la defensa y la seguridad). La primera ya regulaba - como otras directivas que la precedieron - las concesiones de obras (título III, arts. 56 a 65), aunque, en su art. 17, excluía expresamente, en efecto, de su aplicación a las concesiones de servicios definidas en el apartado 4 del artículo ${ }^{26}$. Y la 2004/17 se refería también de modo expreso a las concesiones de servicios para excluirlas igualmente de su ámbito de aplicación, a la vez que a las concesiones de obras cuando unas u otras fueren adjudicadas por las entidades adjudicadoras que ejerciesen las actividades a que se refiere esa Directiva y se adjudicasen precisamente para desarrollar esas mismas actividades. No se entiende por qué, puestos a someter en principio a las concesiones de servicios - y también a las concesiones de obras por las entidades de la Directiva de sectores especiales- a una regulación de directiva, aun con las no pocas limitaciones y condiciones con que lo ha venido a hacer la Directiva 2014/23/UE, no se ha hecho en la misma nueva Directiva general sustantiva (la 2014/24/UE) o —en lo que le correspondiera- en la Directiva de los denominados sectores especiales (la 2014/25/UE). Se han complicado, de entrada, las cosas sin necesidad alguna.

26 «Contrato que presente las mismas características que el contrato público de servicios, con la salvedad de que la contrapartida de la prestación de servicios consista, o bien únicamente en el derecho a explotar el servicio, o bien en dicho derecho acompañado de un precio». 
3. Lo que, en países como Francia y otros bajo la influencia de sus concepciones, venía entendiéndose como concesiones de servicios (públicos, en principio, y, en todo caso, al público, a terceros, aun por cuenta de una Administración) había quedado, en efecto, implícitamente excluido de las directivas de coordinación de la contratación pública, desde que se aprobó la Directiva que por primera vez trato de someter de manera general a este tipo de regulación comunitaria a los contratos de servicios. Tras largo debate en el que no se logró superar la oposición en particular de Francia, el texto final de la Directiva 92/50 no incluyó mención alguna de las concesiones, a pesar de que sí la hubiese en la propuesta inicial de la Comisión ${ }^{27}$. Y aunque el silencio pudo generar dudas sobre si debían considerarse o no incluidas en la amplia definición del contrato público de servicios que hace esa Directiva delimitando su objeto propio, lo cierto es que la Comisión Europea y el Tribunal de Justicia entendieron que habían quedado excluidas. No en vano la Comisión se sintió en la obligación de hacer pública el 12 de abril de 2000 una Comunicación Interpretativa sobre concesiones en el Derecho Comunitario para recordar que aunque las concesiones de servicios no estaban sujetas a las directivas hasta entonces aprobadas - tampoco las de obras en los sectores especiales-, no por ello dejaban de estar sujetas al TCE, a cuyos efectos se señalaban las normas y principios que se desprenden de él, teniendo en cuenta también la jurisprudencia del Tribunal de Justicia. Y ya antes, en su Comunicación sobre la contratación pública en la Unión Europea, de 11 de marzo de 1998, también había afirmado netamente que, entre las concesiones, solo las de obras estaban reguladas en la Directiva general sobre contratos públicos de obras, aunque todas debieran someterse al derecho comunitario originario (ap. 2.1.2.4 $)^{28}$.

27 Lo contó la Comisión en la nota 15 de su Comunicación Interpretativa del año 2000, y, con más detalles, la Sentencia Telaustria, asunto C-324/98, de 7 de diciembre de 2000, cdos. 46-48, añadiendo información sobre lo que de modo similar ocurrió con la adopción de la Directiva 90/531, primera que reguló los contratos en los llamados sectores excluidos (cdos. 49-50). Lo recogería entre nosotros J. Ma . Gimeno Feliú (2002), Contratos públicos: ámbito de aplicación y procedimiento de adjudicación (la incidencia de las Directivas comunitarias en el Ordenamiento Jurídico Español), Madrid: Civitas, nota 198 (pág. 103). Véase también, recientemente, F. L. Hernández González (2016), «La construcción del contrato de concesión en el Derecho de la Unión Europea», en J. Ma. Baño León (coord.), Memorial para la reforma del Estado (Estudios en homenaje al profesor Santiago Muñoz Machado), III (págs. 2452 y s.), Madrid: CEPC.

28 También el TJCE había declarado que las concesiones de servicios estaban excluidas de la Directiva de sectores especiales — pero sometidas al derecho comunitario originario-, identificándolas con los contratos en los que la contraprestación al prestador del servicio consiste en el otorgamiento del «derecho a explotar su propia prestación 
Ha de notarse con todo que, entre las exclusiones de su ámito de aplicación, la Directiva 92/50 había acordado la establecida, de forma no poco enrevesada, en su art. $6^{29}$, que, aunque literalmente podía llevar a pensar en otros supuestos ${ }^{30}$, alguna vez parece haberse utilizado de hecho también para confirmar la exclusión de las concesiones de servicios públicos de la tradición francesa, lo que se pondría de manifiesto, al menos implícitamente, teniendo en cuenta el contexto, en las observaciones escritas del Gobierno francés en el procedimiento de la cuestión prejudicial del asunto C-360/96 suscitada por un Tribunal de la ciudad holandesa de Arnhem, resuelta por STJCE de 10 de noviembre de 1998. La verdad es que esa Sentencia no se detuvo en el argumento expuesto por Francia ${ }^{31}$, ni hizo pronunciamiento explícito en sus

para conseguir así su retribución» (Sentencia Teleaustria, de 2000, cdos. 56-58 y ap. 1(2) del fallo).

29 «La presente Directiva no se aplicará a los contratos públicos de servicios adjudicados a una entidad que sea, a su vez, una entidad adjudicadora con arreglo a la letra b) del artículo 1, sobre la base de un derecho exclusivo del que goce en virtud de disposiciones legales, reglamentarias y administrativas publicadas, siempre que dichas disposiciones sean compatibles con el Tratado».

30 El texto como tal lleva a pensar en efecto no en las concesiones de servicio público sino más bien en los contratos propiamente de servicios que los llamados poderes adjudicadores hiciesen con entidades o empresas de servicio público para recibir de ellas los servicios correspondientes (gas, electricidad...; las telecomunicaciones ya estaban excluidas, en cualquier caso, del concepto de contrato de servicios por el art.1,a) y v) de la propia Directiva 92/50), a condición de que se tratase a su vez de entidades públicas o bajo influencia dominante pública, de modo que fuesen verdaderos organismos de derecho público en el sentido de la Directiva.

31 Dos municipios holandeses habían decidido unificar sus servicios de recogida de residuos y encomendar su gestión a la sociedad anónima ARA que ellos constituyeron, aunque ampliando sus finalidades a algunas otras; únicamente podían ser socios personas jurídicas de derecho público o sociedades de las que al menos el $90 \%$ de sus acciones se hallase en sus manos, y, en su Consejo de Vigilancia, los municipios habrían de designar cinco de los, como mínimo, siete y, como máximo, nueve de sus miembros. Los municipios otorgaron a ARA sendas concesiones para gestionar en exclusiva los correspondientes servicios. Luego hubo otras complejidades que no hace falta traer aquí. Se discutió si el objeto de la relación de ARA con los Municipios correspondientes entraba o no en la exclusión del ámbito de aplicación de la Directiva 92/50 establecido en su art. 6º . El Gobierno francés, personado en el proceso - como otros Gobiernos de la Comunidad- arguyó con contundencia que los contratos entre los municipios y ARA «constituyen concesiones de servicio público y, por tanto, están excluidos del ámbito de aplicación de la Directiva 92/50». Y añadió que «para que exista una concesión de servicio público en el sentido del Derecho comunitario, 
respuestas sobre si se trataba o no de una concesión de servicio público; de hecho, sin embargo, las respuestas que dio a las cuestiones planteadas conducían a que el supuesto de que se trataba quedase, en efecto, fuera del ámbito de la Directiva, en virtud de su art. $6^{32}$.

4. La desconexión formal de la idea de servicio público de la definición de la concesión de servicios que se formalizó en la Directiva 2004/18 y, sobre todo, el indudable afán de las instituciones comunitarias - Comisión, Tribunal de Justicia, particularmente- por ensanchar todo lo posible la efectividad de la aplicación de esa Directiva, más específicamente en cuanto a todo lo que pudiera entrar en el concepto de contratos públicos de servicios por ella regulados —en sustitución ya de la Directiva 92/50—, llevarían a los discutibles criterios seguidos para mover los límites iniciales entre el común de los contratos de servicios y las concesiones de servicios sobre la base de cuestionar lo que realmente pueda significar —abandonada la conexión con la noción francesa y latina de servicio público-explotación del servicio ${ }^{33}$. Esos criterios, inspirados en normas de muy otra finalidad, serían acogidos por el Tribunal de Justicia ${ }^{34}$ y son los que finalmente han pasado a la Directiva 2014/23. No

es preciso que el contratante sea retribuido bien con el derecho de explotación del servicio bien con este derecho acompañado de un precio» (cfr. cdo. 24). No había en realidad aún un texto normativo que dijese tal cosa; solo más tarde lo diría expresamente la Directiva 2004/18 sin adjetivar, sin embargo — significativamente—, al servicio como público.

32 El Tribunal entendió en el caso que no se trataba de interpretar el concepto de [¿concesión de?] servicio público, porque no era objeto de las cuestiones planteadas por el Tribunal holandés, aunque, obiter dictum, aludió a que, en el caso, la retribución de ARA «consiste únicamente en un precio y no en el derecho de explotación del servicio» (considerando 25).

33 Una crítica en M. Fuertes López (2013), «Los riesgos del riesgo de explotación (crítica a la jurisprudencia del Tribunal de Justicia de la Unión Europea sobre las concesiones de servicio público y los contratos de servicios)», en J. Ma. Gimeno Feliú (dir.), Observatorio de Contratos Públicos 2012 (págs. 197-239), Cizur Menor (Navarra): Aranzadi, Thomson-Reuters.

34 Sentencias Eurawaser, de 10 de septiembre de 2009 (asunto C-206/08) («en el marco de un contrato de servicios [...] el derecho a recaudar una remuneración de terceros basta para que dicho contrato se califique como "concesión de servicios" [...] siempre que [el contratista que adquiere ese derecho] asuma la totalidad, o, al menos, una parte significativa, del riesgo de explotación que corre la entidad adjudicadora, incluso si dicho riesgo es, desde el inicio, muy limitado debido a la configuración jurídico pública de los servicios»), y Privater Rettungsdienst und Krankentransport Stadler, de 
habría, pues, tal explotación del servicio si, en efecto, como ahora ha venido a puntualizar su art. 5,1), en su segundo párrafo, aplicable además tanto a las concesiones de servicios como a las de obras, el contrato no implica «transferencia al concesionario de un riesgo operacional en la explotación de dichas obras o servicios abarcando el riesgo de demanda o el de suministro, o ambos». Y como así dicho resultaría no poco indeterminado, se añade que «se considerará que el concesionario asume un riesgo operacional cuando no esté garantizado que, en condiciones normales de funcionamiento, vaya a recuperar las inversiones realizadas ni a cubrir los costes que haya contraído para explotar las obras o los servicios que sean objeto de la concesión. La parte de los riesgos transferidos al concesionario — se continúa diciendo aún- supondrá una exposición real a las incertidumbres del mercado que implique que cualquier pérdida potencial estimada en que incurra el concesionario no es meramente nominal o desdeñable».

He aquí, pues, introducido, en efecto, un criterio definitorio de las concesiones que resulta en cuanto tal ciertamente nuevo y no poco desconcertante, llamado, por lo demás, a suscitar no pocos conflictos, dadas las dificultades de interpretar su alcance ${ }^{35}$.

10 de marzo de 2011 (asunto C-274/09) (el contrato de servicios «debe ser calificado de contrato de "concesión de servicios" [...] cuando la remuneración del operador económico elegido corre íntegramente a cargo de personas distintas de la entidad adjudicadora que ha otorgado el contrato [...] y el operador económico asume un riesgo de explotación, aunque sea muy limitado» porque «no se le garantiza la cobertura íntegra de los costes soportados en el marco de una gestión de sus actividades conforme a los principios establecidos por el Derecho nacional»). Véase F. L. Hernández González (2016), «La controvertida supresión del contrato de gestión de servicios públicos», en El Cronista del Estado social y democrático de Derecho, 60, pág. 50. En ese mismo trabajo (pág. 51) se refiere al Sistema Europeo de Cuentas Públicas (SEC 95 y SEC 2010) —en orden a determinar el nivel de déficit público de los Estados de la UE- como origen de la noción de riesgo asumida por el Tribunal de Justicia. Ha vuelto sobre el tema en (2016), «La construcción del contrato de concesión en el Derecho de la Unión Europea», cit. supra, passim.

35 Se ha referido a las vicisitudes y dificultades de este criterio, entre otros, L. Míguez Macho (2015), "La distinción entre las concesiones de servicios y otros contratos públicos a la luz de la Directiva 2014/23/UE: repercusiones para el Derecho español», capítulo XVII de J. Ma Gimeno Feliú et al., Observatorio de los contratos públicos (Ponencias sectoriales $X$ Congreso AEPDA) (págs. 400 y ss.), Cizur Menor (Navarra): Aranzadi, Thomson-Reuters. Véase también Ma Hernando Rydings (2015), «El nuevo marco jurídico comunitario aplicable a los contratos de concesión», en M. Almeida Cerreda e I. Martín Delgado (dirs.), La nueva contratación pública (Actas del I Con- 
5. El objetivo, no obstante, de someter ahora también a las concesiones de servicios a normas establecidas por directiva — superando aparentemente la situación que determinaban las Directivas 2004/17 y 2004/18 — ha sido en realidad bastante reducido, como ya hemos apuntado, por una serie de exclusiones expresamente establecidas en la misma Directiva 2014/23, que afectan específicamente a concesiones de servicios públicos ${ }^{36}$.

El ámbito real de las concesiones de servicios sometidas a la Directiva queda, a partir de ahí, manifiestamente recortado, aunque se produzca la paradoja de que, en razón del criterio del riesgo operacional, cabrá entender ahora que si en la concesión de servicio público no hay tal riesgo operacional, el contrato sería un contrato de servicios de los sometidos a las reglas generales y más exigentes de la Directiva 2014/24 o, en su caso, de la 2014/25, y por lo tanto ya no sería de aplicación la exclusión, obviamente, del art. 10 de la Directiva 2014/23, siendo más problemático que queden excluidas con la misma amplitud de esas otras directivas a tenor de sus preceptos: su tenor literal no lo ampararían.

Esta sumisión a una de esas otras directivas en tales casos parece, sin embargo, que, por absurda, debería excluirse. Si la misma Directiva de concesiones, que lo que quiere, sin duda, es netamente ampliar el ámbito de lo regulado por las directivas de contratación pública — aun reduciendo a la vez la intensidad de la regulación para los contratos que llama concesiones-,

greso de la Red Internacional de Derecho Europeo) (págs. 93 y ss.), Campus na nube, y, en esta misma obra, E. Vázquez Lacunza (2015), «El impacto del concepto europeo de concesión en el Derecho español», particularmente págs. 291 y ss.

36 Está, para empezar, la exclusión determinada por su art. 10 que, aunque de redacción similar a la de los arts. 6 de la Directiva 92/50, 18 de la 2004/18 e incluso 11 de la 2014/24, al referirse precisa y expresamente a concesiones, obliga a una lectura distinta, que conduciría en realidad a mantener fuera del ámbito de aplicación de la Directiva de concesiones prácticamente todas las que en varios países se conocen como concesiones de servicio público, en cuanto actividad objeto de un derecho exclusivo o servicio, reservada en suma a la titularidad pública para su gestión por quien la entidad pública titular disponga. Parte de la diferencia de redacción entre este precepto y los similares de las otras directivas citadas (ya derogadas o vigente, en el caso de la 2014/24) contribuye aún más a reforzar esta conclusión. "La presente Directiva — se dice en el segundo párrafo del ap. 1 del art. 10 - no se aplicará a las concesiones de servicios adjudicadas a un operador económico sobre la base de un derecho exclusivo del que dicho operador goce con arreglo a una norma, reglamento o disposiciones administrativas nacionales aplicables y cuya concesión se ajusta al TFUE y a actos jurídicos de la Unión que establecen normas comunes de acceso al mercado aplicables a las actividades contempladas en el anexo II». 
excluye las concesiones de servicio público en sentido estricto —en razón de su exclusividad-, carece de toda justificación que se las considere sometidas a las directivas generales por el solo hecho de que en realidad no encajen en la noción de concesión impuesta por la Directiva, que exige la traslación al concesionario de un riesgo operacional. Es muy difícil aceptar que se haya previsto y querido esta consecuencia.

Por lo demás, de la comentada exclusión resultaría con suficiente claridad que lo que la Directiva llama concesiones de servicios es - a efectos prácticos- algo de suyo distinto de lo que siempre hemos entendido por concesiones de servicio público en su sentido más estricto, lo que ya legitimaría el mantenimiento de esta categoría en el derecho interno, aun eventualmente añadiendo precisiones para que solo se aplique a servicios públicos gestionados efectivamente con derechos exclusivos.

Algunas otras exclusiones contenidas en la Directiva confirman aún esto o incluso permiten ampliar la noción de concesión de servicio público a la de algunos servicios esenciales o de interés económico general eventualmente sin derechos exclusivos, como el transporte aéreo o el de viajeros (art. 10.3), o redes públicas de comunicaciones y servicios de comunicaciones electrónicas (art. 11), o, en fin, los servicios hidráulicos (art.12, aunque no pocos se prestarán también exclusivamente).

6. Lo más importante, sin embargo, es no perder de vista la razón de ser del concepto de concesiones de obras o de servicios ahora establecido en la Directiva 2014/23, que no es otro que el de determinar ciertas especificidades en cuanto a las reglas establecidas por la Unión para los contratos públicos y asimilados. Lo que le importa a la Unión es que los Estados aseguren en sus ordenamientos que se logra el resultado normativo de que todos los contratos públicos y asimilados que reúnan esas características no dejen de someterse al menos a esas reglas de la Directiva 2014/23, a partir de las cuantías que se fijan. No le importa que las normas nacionales puedan ser incluso más exigentes. Y obvio es que para que los Estados cumplan con las obligaciones que para ellos imponen estas directivas, bastará con que lo que estas llaman contratos públicos de servicios y concesiones de servicios se sometan en el derecho estatal, como mínimo, a las exigencias establecidas para unos y para otras en esas directivas, se llamen como se llamen esos contratos o/y concesiones en el derecho nacional y sea cual sea, en lo demás, su régimen jurídico.

La cuestión no puede ser más sencilla ni más clara, por tanto. Prescindiendo ahora de lo relativo a los sectores especiales, que tienen en el derecho español su ley propia, sobre la que ahora no haremos comentarios, el régimen legal en España de los contratos públicos o equiparados a estos efectos, que, por sus caracteres subjetivos y objetivos, han de someterse a lo establecido en 
las Directivas 2014/24 y 2014/23 para los que ellas llaman contratos públicos de servicios y concesiones de servicios, debe garantizar, en efecto, cuantas exigencias marcan esas directivas. Eso es todo. Da igual cómo se llamen, repetimos, y cuál sea el resto de su régimen jurídico.

7. La verdad es que no son muchos los cambios que habría que introducir. No nos detendremos ya en puntualizarlos. Importa, sin embargo, insistir en que, desde luego, ninguna razón específicamente comunitaria habrá - fuera, por ende, de lo que pueda ser aconsejable por motivos ajenos a las obligaciones con la Unión- para introducir más cambios en el régimen de los contratos de gestión de servicios públicos con cuantía de relevancia comunitaria que los que pudiese requerir la aplicación de la Directiva 2014/23 a aquellos de entre ellos a los que debiera aplicarse — si se hace una interpretación no estricta del servicio público en la delimitación del objeto de ese contrato- porque no estén ya garantizadas las correspondientes exigencias en nuestra legislación vigente. Lejos, desde luego, de cualquier supresión de esa modalidad contractual tradicional en nuestro derecho ${ }^{37} \mathrm{o}$ de la modificación de cualquier aspecto de su régimen jurídico no contradictorio con lo exigido por la Directiva. Si alguno de esos contratos de gestión de servicio público pudiera referirse a prestaciones no propiamente de servicio público en sentido estricto y sin traslación de riesgo operacional, habrían de garantizarse las exigencias de la Directiva 2014/24 para los contratos de servicios, si su cuantía tiene relevancia comunitaria y no se incluyen en ninguna de las exclusiones de su aplicación que contempla dicha Directiva. No habría necesidad alguna de configurar formalmente unas concesiones de servicios distintas de las concesiones y —más en general- de los contratos de gestión de servicios públicos. Y, desde luego, cosa bien distinta — también respecto del contrato de servicios- habrá de ser en cualquier caso lo que algunas disposiciones comunitarias ya hace años denominaron contrato de servicio público y ha sido recibido por algunas normas

37 No encontramos fundadas tesis, como la expuesta por M. Ma Razquin Lizarraga (2012), «El contrato de gestión de servicios públicos: la necesaria reconducción de este tipo contractual (Comentario a las Sentencias del TJUE de 29 de abril de 2010 y de 10 de marzo de 2011)», en E. García de Enterría y R. Alonso García (coords.), Administración y Justicia (Un análisis jurisprudencial), Liber amicorum Tomás-Ramón Fernández, vol. II, (págs. 3549-3573), Cizur Menor (Navarra): Civitas, ThomsonReuters, o la que sirve de base a F. J. Villar Rojas (2016), «La resiliencia del contrato de gestión de servicio público frente a las normas europeas de contratación pública», capítulo 8 de F. L. Hernández González (dir.), El impacto de la crisis en la contratación pública (España, Italia y Francia) (págs. 286-287), Cizur Menor (Navarra): Aranzadi, Thomson-Reuters. 
de nuestro derecho ${ }^{38}$, porque no tiene por objeto un servicio de la Administración ni servicio alguno en beneficio de ella, sino la financiación obligada por parte de esta de una especial obligación de servicio público que asumen operadores de un servicio de interés general ${ }^{13}$.

8. Lo que carece de cualquier justificación inteligible es que la inclusión de las comentadas concesiones de servicios en el nuevo paquete de directivas de 2014 sobre contratación pública pueda interpretarse razonablemente como una especie de cambio de paradigma al que las legislaciones nacionales y la doctrina jurídica habrían de rendirse sin remedio, con la consiguiente obligación de modificar radicalmente arraigadas tradiciones conceptuales y regulatorias sobre los contratos de concesión administrativa de servicios y aun todo lo relativo, en el caso español, a la figura del contrato de gestión de servicios públicos. En absoluto cabe derivar del paquete de directivas de contratación pública de 2014 ni de ninguna otra exigencia normativa o jurisprudencial de la UE requerimiento alguno en tal sentido. Advertencias en este sentido se han venido haciendo ya al Gobierno, por parte del Consejo de Estado y de otras instancias.

38 Véase F. J. Villar Rojas (2016: 300-301).

39 Hace ańos tuvimos ya oportunidad de explicarlo con motivo del Reglamento CEE 1893/91, de 20 de junio, que modificó el 1191/69, relativo a las obligaciones inherentes a la noción de servicio público en el sector de los transportes por ferrocarril, por carretera y por vía navegable: (1994), «El Derecho de la postprivatización», en Primeras Jornadas sobre regulación económica e iniciativa privada, Buenos Aires: Universidad Austral, septiembre de 1993, publicado parcialmente como «La regulación económica en España», Revista Argentina del Régimen de la Administración Pública, 184, págs. 11-18. De nuevo en (1997), «La regulación económica en España», en G. Ariño, J. M. de la Cuétara y J. L. Martínez López-Muñiz, El nuevo servicio público, Madrid: Marcial Pons, págs. 250 y ss. I. de los Mozos Touya analizó la aplicación de la figura a los consorcios educativos [(1995), Educación en libertad y concierto escolar, Madrid: Montecorvo, págs. 366-377], y al transporte de viajeros en el ámbito rural [(2000), «Obligaciones especiales de servicio público en el transporte rural», REALA, 282, págs. 119-156, también en (2001), Nuevas perspectivas del Régimen Local. Estudios en Homenaje al Profesor José Ma Boquera Oliver (págs. 1433 a 1471), Valencia: Tirant lo Blanch]. 
